ject at all was not with the view of magnifying mine office and exalting the special branch which I happen to represent, but because, as you so aptly putit, " there are so many overwhelming reasons why this branch of art cannot be made an exclusive specialty, but must always form part of general practice."

Adopting this view of the question, I attempted to show that, "education, according to Paley, comprising every preparation that is made in our youth for the sequel of our lives," it becomes a serious question whether some important measure ought not at once to be adopted in order to remedy the glaring defect in the present system of education as regards midwifery in its most extended sense, including diseases of women and children.

The theoretical instruction given is far too scant, considering the importance of the subject in the daily routine of general practice, and the opportunities for acquiring a practical knowledge of operative midwifery are almost nil as regards the bulk of medical students. I am, Sir, yours faithfully,

Wimpole-street, Oct. 7th, 1878. ARTHuR W. EDIS.

\section{CARBOLIC ACID IN SMALL-POX.}

To the Editor of THE LANCET.

SIR,-The discussion on this subject has tended to prove :-

1. The comparative failure of the diluted acid, in aborting the eruption of small-pox.

2. The need of further investigation in this direction.

I hope they will be undertaken by those who have the opportunity, as it is pretty certain that very good results may be attained.

It may be well to point out that nitric acid, used as I have suggested, causes no eschar, and therefore no cicatrix. With the single exception of not producing local anæesthesia, its action is the same as that of carbolic acid. When applied to the sound skin, it kills the cuticle only.

I am, Sir, yours truly,

Lynn, October 8th, 1878 .

JOHN LOWE.

\section{MANCHESTER.}

(From our oun Correspondent.)

THE Medical Board of the Manchester Infirmary have recently decided to admit the students to their weekly consultations, after the custom adopted at St. Bartholomew's. The first open consultation was held in the theatre last Thursday, when several of the senior students availed themselves of the opportunity thus afforded of hearing the cases discussed by the different members of the honorary staff. The case is first briefly commented upon by the surgeon or assistant-surgeon introducing it; then questions are put by any member of the staff, and afterwards, the patient having left the room, the opinions of the members present are taken, beginning with the junior, and passing to the senior surgeon.

The first meeting of the Manchester Medical Society for the session '78-79 was held on Wednesday, Oct. 2nd, at the Owens College, when several interesting communications were made to a very large meeting. Dr. Dreschfeld showed a cerebral tumour removed from the brain of a boy of exceedingly rare and interesting character. The tumour, which was the size of an ordinary fist, had a central nucleus of dense bone embedded in a mass of gliomatous structure. Mr. Bradley showed a man whose tongue he had recently removed with scissors, after the method originally suggested and practised by Mr. Whitehead. He considered that, with "a good light, a good table, a good gag, and a good assistant," it was a perfectly simple and safe operation. $\mathrm{Mr}$. Lund endorsed this statement, and, commenting on this and other like cases, gave it as his opinion that $\mathbf{M r}$. Whitehead's operation was by far the best yet introduced for removal of the tongue. Subsequently Dr. Ross interested the meeting with a demonstration of microscopic specimens, magnified and thrown on to a screen, illustrative of the anatomy and pathology of the spinal cord. The specimens, which were beautifully prepared, will form a lasting memorial of $\mathrm{Dr}$. Ross's admirable labours as pathologist to the hospital, a post which he has now vacated in expectation of being elected assistant-physician to the Infirmary, which appointment may be confidently anticipated to take place in a week or two.

The students' annual dinner, which is, perhaps, chiefly remarkable for the absence of students, was held at the Queen's Hotel, on Friday, Oct. 4th, under the presidency of Dr. Gamgee. The evening was pleasantly enough spent, but under its present form its raison d'être is not easy to see, any more than that of the abandoned introductory lecture. This, at least, brought all the students together, and all their teachers, too. The present plan accomplishes neither" one thing nor another, and it seems clear that if the custom is worth continuing there should be two dinners, one for the hospital and college staff, and one for the students. Probably the best plan of all would be for the Owens College to give a soirée or a conversazione on the opening of each winter session, which would be available for all the various departments of the College. As matters at present stand, a lecture is given introductory to the commencement of the session of the arts, science, and law departments, and another to the evening classes, while the large and important medical department is left in the cold. The fresh entries at the College are more numerous than they have ever hitherto been, but as the days of registration have not yet expired, I cannot give you the exact number.

Manchester, Oct. 8th, 1878 .

\section{THE PARIS EXHTBITION. (From our Paris Correspondent.)}

\section{VIII.-THE BRITISH SECIION (CONTINUED).}

THE Silicate Paint Company of Seel-street, Liverpool, have a very interesting show-case, in which they have exhibited specimens of their silicate paint, dry and ground in oil ; silicate enamelling paint ; silicate petrifying liquid for damp walls, and as a cheap washable internal decoration in lieu of wall paper ; and silicate marine and antifouling paint, for use on board ship. On account of the hygienic aspects of this exhibit, it is right to notice its most striking features. Thus the silicate paint is not only remarkable for durability and brilliancy of colour, and its hardness or density, but also for its harmless character, as it is free from lead. It dries rapidly, and forms a polished surface which is said to resist atmospheric influences, the action of heat, and that of the various gases which discolour lead paint. It has no chemical action, and protects the wood or metals to which it is applied. The enamel paint is still more deserving of notice from a hygienic point of view, as, on account of its hardness and polish, it forms a porcelain-like surface, which renders it washable; and as it is impervious to water, it is useful against dampness of walls. Water hardens this paint instead of softening it. On account of these properties it may prove of great use for hospitals and public establishments as.well as for private dwellings. Its other properties are those of the silicate paint, in addition to which it dispenses with a coat of varnish. 'The petrifying liquid is a very interesting article. It is an innocuous water paint, with the property of hardening in the air, and of sealing hermetically the pores of bricks, tiles, cement, and plaster, and thus rendering them impervious to moisture. It is shown in two forms. One is a paste of various colours which can be diluted with hot water; the other, a transparent liquid ready for use. This latter is especially employed for hardening and preserving soft stones or bricks without changing their colour. It also forms a durable wall-covering which may be used for colleges, hospitals, churches, \&c., in lieu of common paint, and with the great sanitary advantage of forming a hard non-absorbent surface. It may, in like manner, be applied to brick and stone floors. The silica from which this liquid is prepared is stated to be obtained from a unique deposit supposed to be of volcanic origin.

Messrs. H. and T. Kirby and Co., of Oxford-street, London, have a most varied and extensive exhibit in an elegantly arranged show-case. Perhaps the most noticeable articles contained in it are their miniature dispensaries for medical practitioners. The portable cases have been contrived both to be carried easily on a journey and to allow practitioners to dispense at the same time that the patient is visited. Messrs. 